TECHNICAL TRANSACTIONS 11/2017

CZASOPISMO TECHNICZNE 11/2017

CHEMISTRY

DOI: $10.4467 / 2353737$ XCT.17.192.7421

Krzysztof Skrzypek (krzysztofskrzypek93@gmail.com)

\title{
Robert Grzywacz
}

Department of Chemical and Process Engineering, Faculty of Chemical Engineering and Technology, Cracow University of Technology

THE MIXING HYDRODYNAMICS AND EFFICIENCY OF THE VENTURI JET MIXER

HYDRODYNAMIKA I WYDAJNOŚĆ MIESZANIA W MIESZALNIKU

Venturiego

\begin{abstract}
This article presents results of the numerical analysis of performance of the Venturi tube, used and applied as type of static liquid-liquid mixer. The calculations were performed for a binary acetone-benzene system of completely miscible Newtonian liquids. Several variables used to describe hydrodynamics of the Venturi were proposed. The influence of orifice location and inlet velocity on the hydrodynamics and mixing effectiveness is presented. Calculations were performed using CFD methods and the Fluent solver for 2D geometry.
\end{abstract}

Keywords: tank mixing eductor, Venturi jet mixer, liquid-liquid mixing, static mixing, passive mixing

\section{Streszczenie}

W artykule przedstawiono wyniki analizy numerycznej pracy eżektora, wykorzystanego jako statyczny mieszalnik ciecz-ciecz na przykładzie dwuskładnikowego układu aceton-benzen. Określono między innymi wplyw położenia otworków ssawnych na jego parametry hydrodynamiczne oraz prędkości wlotowej surowca na efektywność procesu. Na podstawie symulacji określono ogólną przydatnośćzaproponowanego urządzenia w zamierzonej dla niego roli na podstawie kilku wprowadzonych wielkości. Analizy dokonano metodami CFD przy użyciu solvera Fluent dla geometrii dwuwymiarowej.

Słowa kluczowe: mieszalnik zbiornikowy, mieszalnik Venturiego, mieszalnik statyczny, mieszanie pasywne, mieszanie cieczy 


\section{Introduction}

Mixing is one of the most important industrial processes and one of the fundamental unit operations of Chemical and Process Engineering. It can be defined as both a process and its result that increases homogeneity of the system. Uniformity is crucial from the perspective of the product quality, but often of process efficiency as well, as macroscopic mixing can greatly supplement other transport phenomena. Despite its apparent simplicity, it remains one of the most complex operations and can be very difficult to carry out efficiently in terms of time and energy spent. There are several main reasons for this:

- The variety of substances that need to be mixed together and their individual and group properties;

- The multitude of ways mixing can be achieved, which raises the question of whether the method one intend to use is really the most efficient;

- The desired degree of product homogeneity, which is always a non-linear function of process time and conditions, and needs proper optimization.

This involves a vast amount of practical knowledge, as it is not possible to be covered purely by theory. Most of the mixing is performed in an individual apparatus through the use of rotating parts e.g. impellers or propellers, that mechanically agitate the fluids and promotes random particle relocation. Such a method is most often called active or dynamic mixing, as it needs an external source of energy to operate. In terms of results it is an efficient, but not always cost-efficient method, as keeping the engine working and agitator rotating continuously is considerable expense. The second group of mixing methods involve using the fluid's own internal energy and does not involve moving mechanical parts. Such techniques are known as passive or static mixing. In such apparatus, agitators are replaced with certain features of flow geometry that can lead to the development of hydrodynamic patterns that enhance both mechanical mixing and mass transfer. This is usually done by reorienting the flow, splitting the streams, joining them together and so on.

The advantages of static mixing are numerous, and are laid out below, as cited from [1]:

- Overall simplicity; static mixers are easy to construct and integrate with existing installations;

- Minimal maintenance; there are no moving parts that need to be serviced regularly;

- Low costs; static mixers are way cheaper to construct and operate than dynamic mixers;

- Process safety; ideal for handling flammable or fragile media, as they do not cause intense friction.

It should be noted that in a way, static mixers also use an external source of energy (pumps or fans). However, these are necessary anyway to operate any kind of chemical installation, and therefore it is not considered to be a downside. One of real disadvantages of static mixer is that each one needs to be specifically designed for an individual process, as there is minimum or even no option for automatic regulation. This encourages more reliance on simulations, which are way cheaper and faster than constructing several variants of apparatus and subsequent experiments. 


\section{Venturi jet mixer}

Most of the common static mixers have the form of a pipe with helical or screw-like inserts of varying pitch, usually called Kenics mixers. The other kind is jet mixers, which use the high-velocity jet of one fluid, pumped into the environment of the other fluid. The device researched in this paper make use of an ejector, presented on the 2-D schematic below.

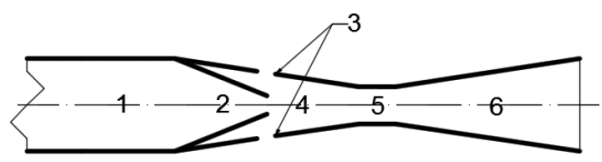

Fig. 1. Ejector: 1 - inlet, 2 - reducer, 3 - side orifices, 4 - mixing chamber, 5 - throat, 6 - nozzle

It performs its role thanks to the Venturi effect. The stream of one liquid, henceforth called the motive fluid, is pumped through the main inlet (1) and flows through the reducer of the ejector (2), where it increases its velocity to maintain continuity of flow. In consequence, static pressure decreases in accordance with the Bernoulli principle. This creates a zone of vacuum pressure and causes a suction effect that draws the secondary, "passive" fluid from the surroundings of the device through side orifices (3) and into the mixing chamber (4). Streams are collided there, accelerated in the throat section (5) and recompressed in the nozzle (6), through which resulting mixture is discharged outside. The apparatus analyzed in this paper consists of such an ejector inserted into the tank and submerged in the initial layer of one processed liquid.

In this paper, a device of this kind was combined with a tank and inlet pipe, thus constituting whole apparatus as presented in Figure 2. It is intended to work in a periodic way. First, pump $P$ is turned on with $V_{1}$ valve opened $\left(V_{2}, V_{3}\right.$ valves being closed) and the pure motive fluid is pumped into the tank and passes through the ejector $R$, up until the desired proportions between the substances is obtained. After that, $V_{1}$ valve is closed and $V_{2}$ is opened, so that the tank contents are sent through the recirculation loop for several more mixing cycles. After obtaining the desired uniformity, the pump is turned off, $V_{2}$ valve is closed and $V_{3}$ is opened. As a result, the whole mixture is discharged from the tank and the apparatus is ready for processing a new batch of substances. Inside the device, mixing essentially occurs during two distinct stages, first in the mixing chamber of the ejector and then in the tank itself.

Devices of this kind are already known in the industry under the name of tank mixing eductors, as found in several catalogues $[2,3]$, however the name applied in this paper was given by Sundararaj in his papers. In spite of their simplicity of construction and operation, such devices have not been the subject of such intense research as was the case in other kinds of mixers. Some specific data is known only by its industrial manufacturers and the articles by Sundararaj [4-6] remain as the only ones significant in the scientific field (at least concerning liquid-liquid mixing). To provide some more readily available info about such devices was the main motivation behind this paper. It should be noted however, that only preliminary research was conducted and it should be treated as a kind of guideline for future investigation and beginning of the research process, and not by any means its decisive conclusion. 


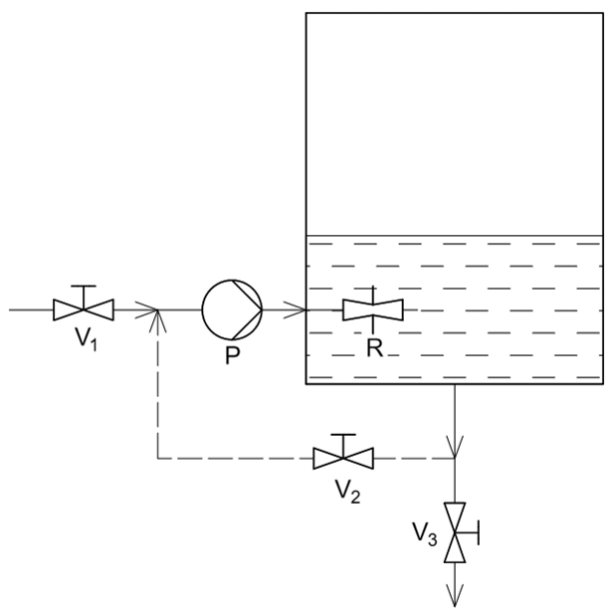

Fig. 2. Venturi mixer with supporting devices: $V_{1}, V_{2}, V_{3}$ - shut-off valves, $P$ - pump, $R$ - ejector; dashed line - recirculation loop, continuous line - inlet and outlet pipes, arrows - flow direction

\section{Simulation setup details}

Simulations were prepared and conducted using the ANSYS Workbench 17.2 components: Design Modeler, Meshing Tool and Fluent Solver, for 2-D planar geometry. The model used for calculations was the Standard k- $\omega$, because of its simplicity and good convergence results. Species transport was also enabled, thus whole flow model consisted of six partial differential equations in the function of time and space.

a) Continuity

$$
\frac{\partial \rho}{\partial t}+\nabla \cdot(\rho \vec{v})=0
$$

The first term stands for the accumulation of mass and second for its inflow and outflow.

b) Motion

The results shown in Table 2 exhibit a high convergence of the test outcome. The difference in force obtained by numerical tests in Abaqus relative to the actual sample is only $4.6 \%$. The corresponding difference in Deform-3D is exactly $10.4 \%$.

$$
\begin{gathered}
\frac{\partial(\rho \vec{v})}{\partial t}+\nabla \cdot(\rho \vec{v} \vec{v})+\nabla p-\nabla \cdot(\overline{\bar{\tau}})-\rho \vec{g}-\nabla \cdot\left(\rho v_{x}^{\prime} v_{y}^{\prime}\right)=0 \\
\left.\overline{\bar{\tau}}=\mu\left[\left(\nabla \vec{v}+\nabla \vec{v}^{\prime}\right)-\frac{2}{3} \nabla \cdot \vec{v} \cdot I\right)\right]
\end{gathered}
$$

The first term of Eq. $2 \mathrm{a}$ is accumulation of momentum per unit volume, the second addition through convection, the third and fourth through molecular transport, the fifth accounts for gravity and the last is turbulent momentum flux due to Reynolds stresses. The stress tensor is computed through Eq. 2 b. 
c) Turbulence equations for the $\mathrm{k}-\omega$ model

$$
\begin{gathered}
\frac{\partial(\rho k)}{\partial t}+\nabla \cdot(\rho k \vec{v})-\nabla \cdot\left[\left(\Gamma_{k} \cdot \nabla \cdot k\right)\right]-G_{k}+Y_{k}=0 \\
\frac{\partial(\rho \omega)}{\partial t}+\nabla \cdot(\rho \omega \vec{v})-\nabla \cdot\left[\left(\Gamma_{k} \cdot \nabla \cdot \omega\right)\right]-G_{\omega}+Y_{\omega}=0
\end{gathered}
$$

With Eg.4, turbulence kinetic energy is computed, while Eg. 5 computes specific turbulence dissipation rate. They are analogous, with the first term of each equation standing for accumulation, the second for inflow or outflow through convection, the third for molecular transport and the final two terms, for generation and dissipation, respectively. The whole model information, along with default constants, as used in ANSYS ${ }^{\circledR}$ can be accessed in [7]. They were left unchanged for the purpose of simplicity of calculations.

d) Secondary phase volume fraction

$$
\frac{\partial\left(\phi_{p} \rho_{p}\right)}{\partial t}+\nabla \cdot\left(\phi_{p} \rho_{p} \vec{v}\right)+\nabla \cdot\left(\alpha_{p} \rho_{p} \vec{v}_{d r . p}\right)-\sum\left(F_{M . q p}-F_{M . p q}\right)=0
$$

e) Species conservation

Chemical species transport is solved for each phase by predicting the local mass fraction of each species, through a solution of convection equation. Diffusion terms are omitted based on solution assumptions.

$$
\frac{\partial\left(\phi_{q} \rho_{q} Y_{s . q}\right)}{\partial t}+\nabla \cdot\left(\phi_{q} \rho_{q} \vec{v}_{q}\right)-\sum\left(F_{M . q p}-F_{M . p q}\right)=0
$$

\section{Simulated case details}

a) System properties

The liquids chosen for the simulations were acetone and benzene, with air as an additional component to fill the rest of the system. Their physicochemical properties were left as default in the Fluent database.

b) Initial conditions

Initially, the tank was filled with a stationary layer of passive liquid of height equal to $45 \mathrm{~cm}$ and air under atmospheric pressure. All variables were therefore equal to 0 , safe from $\omega$ as being equal to 1 .

c) Boundary conditions

Walls were assumed to be smooth and associated FLUENT settings were left as default. The inlet was specified as a velocity inlet and outlet as a pressure outlet. For the outlet, default options were chosen, for the inlet two values were specified: hydraulic diameter and turbulence intensity. 
While in the case of the 2-D problem, the hydraulic diameter is simply the length of the line selected as inlet, turbulence intensity must be properly calculated. Theoretically, it is defined as the ratio of velocity oscillations to the mean, time-averaged value of velocity [8].

$$
I=\frac{v^{\prime}}{\bar{v}}=\frac{\sqrt{\frac{1}{3}\left(v_{x}^{\prime 2}+v_{y}^{\prime 2}+v_{z}^{\prime 2}\right)}}{\bar{v}}
$$

In this paper however, it is computed according to formula provided by Basse in [9]:

$$
I=0.227 \cdot \mathrm{Re}^{-0.1}
$$

This is a strictly empirical equation, accurate only for clearly turbulent and fully developed flows in hydraulically smooth pipes. In no way should it be taken as measure of turbulence itself, it only describes the magnitude of fluctuations relative to the average velocity.

d) Variables introduced

This study makes use of several parameters that describe the various aspects of mixer performance, which were used for making plots and figures, as well as for general estimation of the process effectiveness.

Pumping coefficient, $\Pi$, is the total volume of mixture drawn into the mixing chamber per unit volume of the inlet motive liquid. Based upon a similar variable used by Sundararaj in [5].

$$
\Pi=\frac{\sum F_{v, \text { orifices }}}{F_{V, \text { inlet }}}
$$

In this formula, $F_{V \text {,inlet }}$ is the volumetric flowrate through the main inlet, while the sum in the numerator denotes the combined volumetric flowrates through side orifices.

Pressure ratio, $P^{*}$, relates the pressure drop in the Venturi tube to the pressure drop that would lead to cavitation. In order to secure the process from vaporization of the stream, its value should not approach 1 .

$$
P^{*}=\frac{P_{i n}-P_{\text {mix }}}{P_{\text {in }}-P_{v}}
$$

Where, $P_{\text {in }}$ stands for pressure at the inlet, $P_{\text {min }}$ being minimal pressure measured in the ejector, and finally, $P_{V}$ as the saturated vapour pressure of acetone under process conditions. Acetone was chosen as a reference because it is more volatile then benzene. The value of $P_{V}$ remain constant at $24571,7 \mathrm{~Pa}$, as indicated by calculator provided on the website of Dortmund Data Bank [10].

Mixing cfficiency, $m_{\text {eff }}$ will be used as a measure of process effectiveness, and the formula according to which it was calculated is presented below:

$$
m_{\text {eff }}=\left(1-\frac{\left|\bar{w}_{c}-w_{c, \text { ideal }}\right|}{\left|1-w_{c, \text { ideal }}\right|}\right) \cdot 100 \%
$$


When its value is 1 , it means that mixture is perfectly mixed, while a value of 0 denotes that the component is pure and as a consequence, that means total segregation. As for the symbols in the formula, these are the mass fractions of the reference component - a measured one and one corresponding to the maximal uniformity state, respectively. For benzene as a reference component in acetone-benzene binary system of 0.5 volumetric ratio of benzene, the latter is equal to 0.5252 .

Dimensionless length, $\mathrm{z}$, is quite often used in analysis of the elongated objects like pipe or tower reactors, to make results appear more universal and intuitive.

$$
z=\frac{x}{L}
$$

In the formula for $z, x$ denotes a position within an ejector (counted from its inlet along the central axis), with $L$ being its total length. Therefore, $z$ value ranges between 0 at the inlet and 1 at the outlet.

e) Geometry

Calculations were performed for the type of ejector presented in the schematic below, together with dimensions and corresponding dimensionless length.

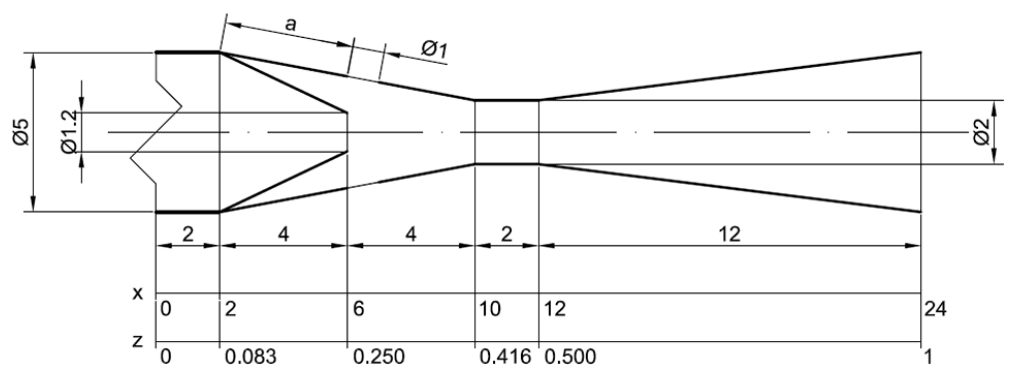

Fig. 3. Detailed ejector schematic, length unit - centimeter, a is a variable

It was used as the insert into the tank of height equal to $120 \mathrm{~cm}$ and diameter of $100 \mathrm{~cm}$. An air outlet was also added in order to simplify the model and omit the compressibility. The meshed geometry of the ejector with its immediate surroundings is presented below.

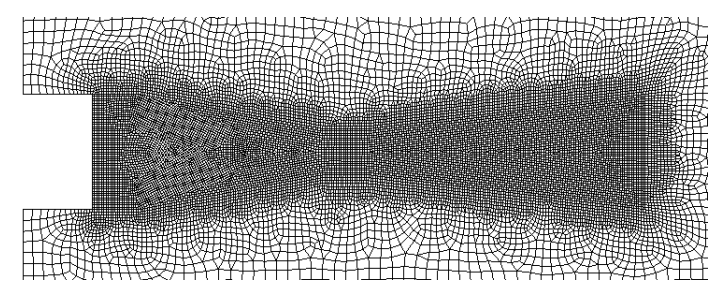

Fig. 4. Ejector mesh

As it may be observed, the mesh inside to the ejector is very fine, as the conditions here are predicted to be very turbulent, contrary to the volume of the tank where mesh was made far coarser because of its greater size. 


\section{Presentation of the results}

Calculations were performed for several chosen values of $a$, as well as inlet velocities of $0.5,1.0,1.5$ and $2.0 \mathrm{~m} / \mathrm{s}$, with acetone as motive liquid and benzene as passive liquid.

a)

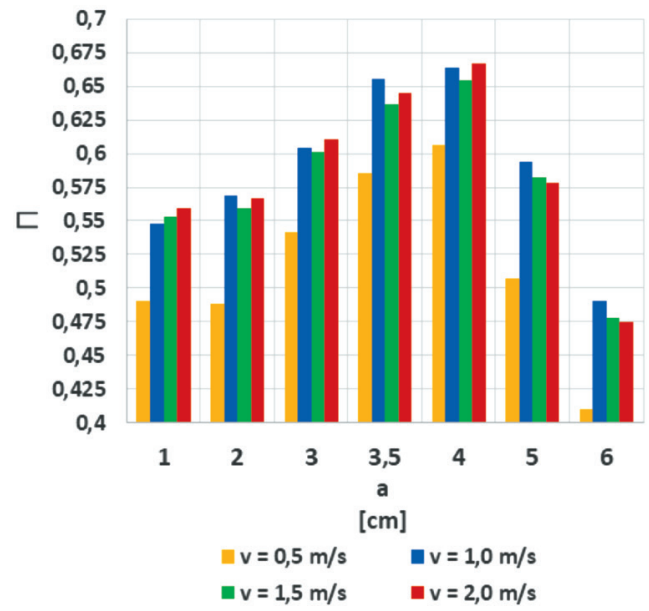

b)

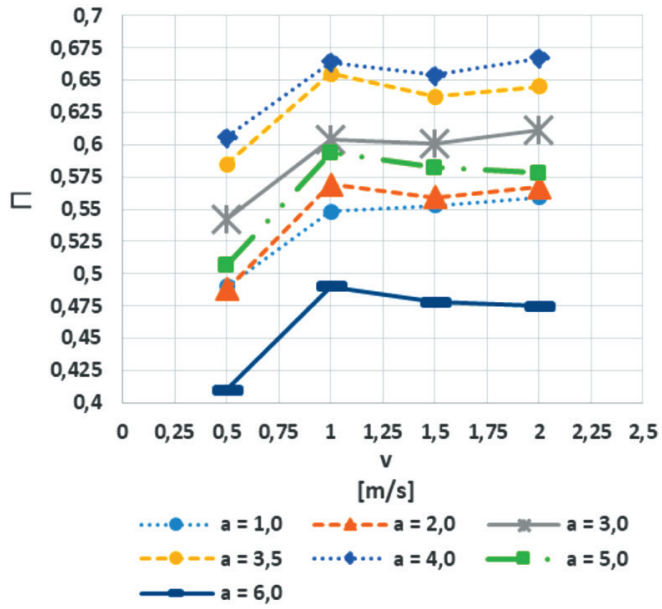

Fig. 5. a) Pumping coefficient vs inlet location; b) Pumping coefficient vs inlet velocity

a)

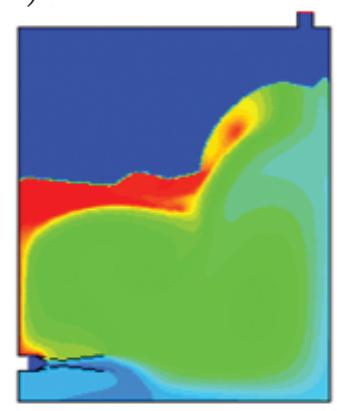

b)

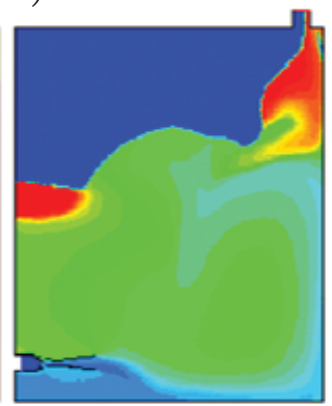

c)

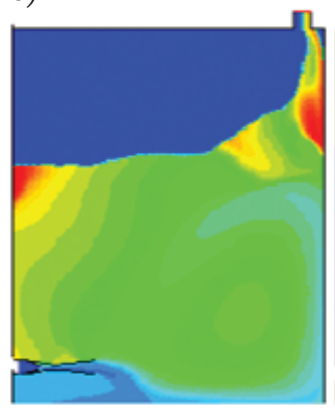

d)

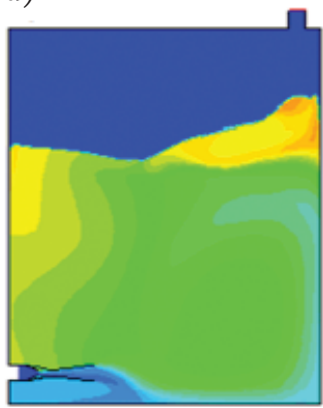

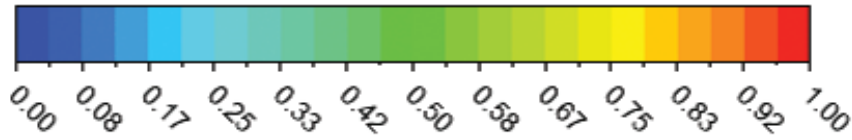

Fig. 6. Contour plots of benzene mass fraction for various inlet velocities: a) $2.0 \mathrm{~m} / \mathrm{s}$; b) $1.5 \mathrm{~m} / \mathrm{s}$; ) $1.0 \mathrm{~m} / \mathrm{s}$; d) $0,5 \mathrm{~m} / \mathrm{s}$

As it may be seen, the pumping coefficient is mainly dependent on the geometry and only a minuscule dependence on velocity was determined, visible only when comparing its lowest values with greater ones, for which it stays almost constant with apparently random oscillations.

It is easily visible on the plots above that some numerical artifacts are clearly present, caused perhaps by the simplicity of the flow model and the 2-D geometry, however the rest of the result 
seems pretty promising. In all cases, acetone ended up as quite evenly distributed across the volume of the tank and finely mixed with the initial amount of benzene. Better results were obtained for lower injection rates, however it should be remembered that it is only first stage of the whole process, and it is intended to be repeated for several more mixing cycles. In all cases, the worst mixing occurred for the top and bottom layers of the fluid, especially for high injection rates. This was again caused by the limitations of 2-D geometry, as the bottom section of the tank was essentially isolated from the rest of the tank by the inflowing stream of acetone, while the top portions of the liquid phase were pushed up by its accumulation. This would not occur in a real 3-D process, in which some kind of circulation would be expected.

In addition to contour plots, average mixing efficiency was presented for different zones within the tank in the figure below. This was calculated on the basis of data taken from several representative points (three for region below the ejector, three near its outlet and up to nine points above it).

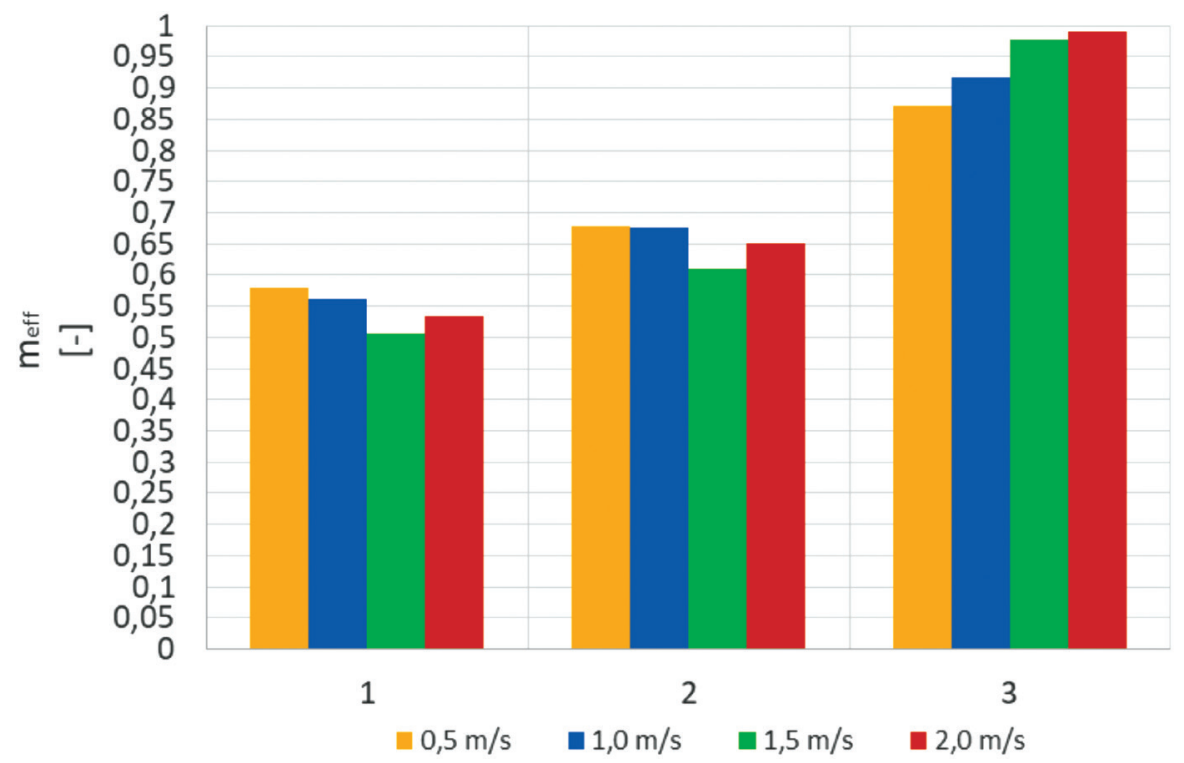

Fig. 7. Mixing efficiency for each zone: 1 - bottom, 2 - middle, 3 - top; a) $2.0 \mathrm{~m} / \mathrm{s}$; b) $1.5 \mathrm{~m} / \mathrm{s}$; c) $1.0 \mathrm{~m} / \mathrm{s}$; d) $0.5 \mathrm{~m} / \mathrm{s}$

The results presented in Figure 7 are further proof of what was observed on the contour plot. Liquids ended up as quite thoroughly mixed in the core of the tank, with lesser degree of mixing near the ejector and sections isolated by its presence. Introducing recirculation seems a reasonable and simple option and perhaps it will be a part of the next research case. In this paper however, only this first stage of the process was analysed.

The next results presented in the Figures 8 and 9, show the computed gauge pressure at the centreline of the ejector, with gauge pressure being essentially the deviation from the reference value of $1 \mathrm{Atm}$. Pressure losses and their magnitude are understood as crucial in operating such a device. 


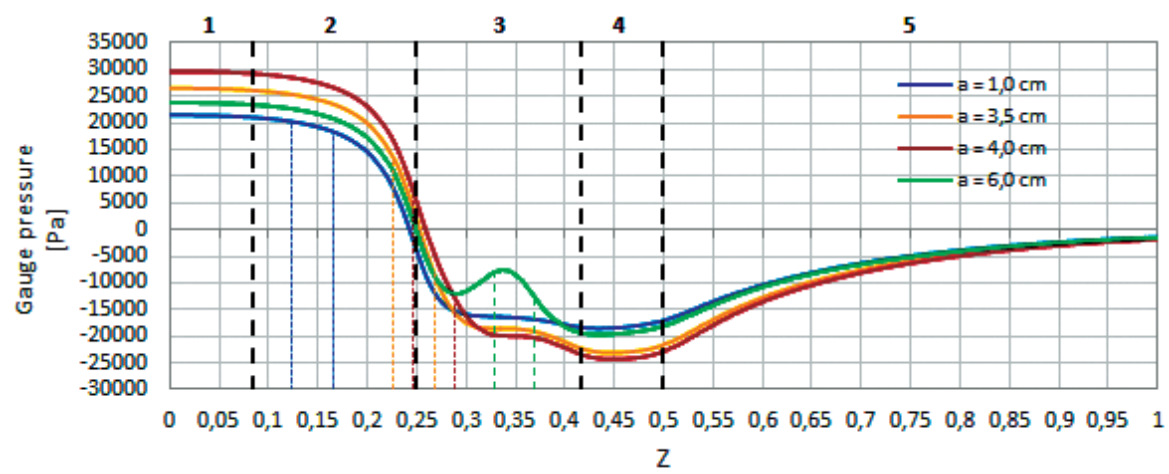

$[-]$

Fig. 8. Gauge pressure profiles along the ejector centreline for inlet velocity of $2.0 \mathrm{~m} / \mathrm{s}$ and various locations of orifices (shown with colored dashed lines); thick dashed lines divide the plot according to Venturi geometry;

1 - inlet section, 2 - reducer section, 3 - mixing zone, 4 - throat section, 5 - nozzle section

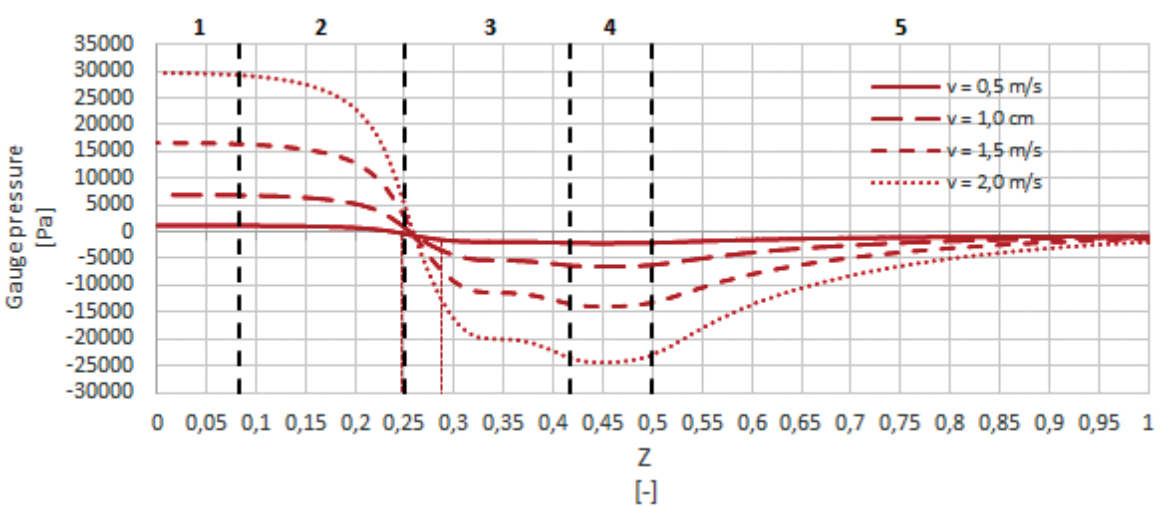

Fig. 9. Gauge pressure profiles along the ejector centreline for dimension $a=4.0 \mathrm{~cm}$ and various inlet velocities; thick dashed lines divide the plot according to Venturi geometry; 1 - inlet section, 2 - reducer section, 3 - mixing zone, 4 - throat section, 5 - nozzle section

It can be observed that greatest pressure drop in the analysed case, occurred not in the mixing zone nor reducer, but in the throat section of the ejector. This is fine, as it encourages the flow in the longitudinal direction of the device, while pressure drop in the mixing chamber is still reasonable. One thing to note is that locating orifices further from the reducer leads to a non-optimal profile, as indicated by the green peak on the Figure 8 . The optimal location of orifices that contributes to greatest pressure drop seems to be just at the same coordinate as the reducer's outlet. Together with the analysis of the pumping coefficient results, this proves that its magnitude is indeed dependent on the pressure drop. While analysing Figure 9, it is clearly visible that increasing velocity contributes greatly to pressure drop, thus this should be one of the main concerns when designing or optimizing a device of such a kind. A proper compromise has to be achieved between the financial expenses, process time and mixing efficiency and finally, safety from cavitation. 


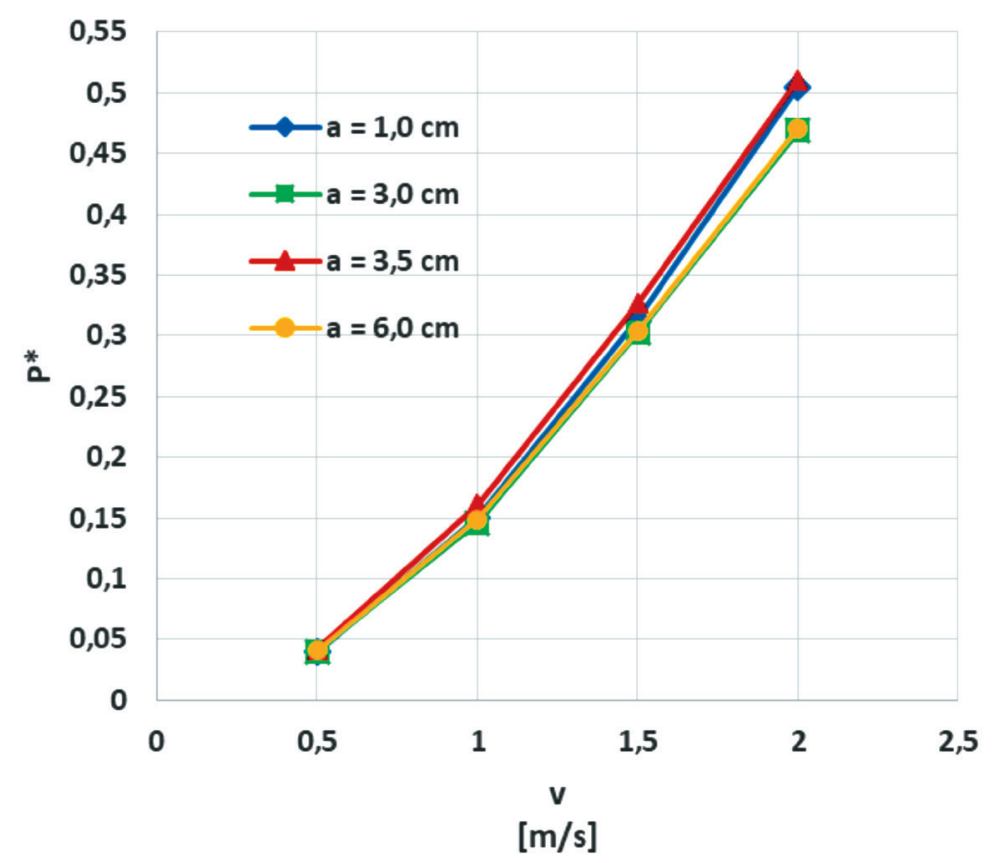

Fig. 10. Pressure ratio for various orifices locations and velocities

As indicated by Figure 10 and previous conclusions, the orifice location has only slight effect on the pressure ratio, which is dependent only on the velocity. Cavitation in the analysed process conditions would not occur, as its value is far from 1 for all cases of orifice location and inlet velocity. It must be noted however, that if greater increase in inlet velocity were needed or demanded, its limiting value must be properly established for every kind of mixed substances and process conditions.

\section{Summary}

As determined before, the calculations performed indicate that a Venturi mixer can potentially be very a efficient, yet simple way of relatively quick and proportional mixing of miscible liquids, like various organic solvents. It can be a decent alternative for traditional tank mixers with propellers or agitators. Of course, it must remembered that because of the limitations of the 2-D model, the results obtained should be taken qualitatively, not quantitatively. Further research is recommended, especially for fully fledged 3-D cases with introduced recirculation and more accurate and realistic assumptions. A stricter optimization of the ejector geometry is recommended, as well as evaluation of the best process conditions in terms of efficiency and expenses. With such questions in mind, perhaps ones for future consideration, this paper is hereby concluded. 


\section{References}

[1] Static mixers: efficient mixing with no moving parts, http://www.entec-international. com/static-mixer.html (access: 10.05.2017).

[2] Eductors \& syphons: Tank mixing eductors, https://www.s-k.com/eductors-syphons/ tank-mixing-eductors.cfm (access: 10.05.2017).

[3] A Guide to Optimizing In-Tank Agitation and Mixing Using Eductors, www.spray.com/ literature.../B635_Tank_Mixing_Eductors.pdf (access: 10.05.2017).

[4] Sundararaj S., Selladurai V., The effects of arbitrary injection angle and flow conditions on Venturi-jet mixer, Thermal Science, 16.1, 2012, 207-221.

[5] Sundararaj S., Selladurai V., Flow and Mixing Pattern of Transverse Turbulent Jet in VenturiJet Mixer, Arabian Journal for Science and Engineering, 38.12, 2013, 3563.

[6] Sundararaj S., Selladurai V., Numerical and Experimental Study on Jet Trajectories and Mixing Behavior of Venturi-Jet Mixer, Journal of Fluids Engineering, 132.10, 2010, 101104-1-9.

[7] ANSYS Workbench documentation, Release 17.2, Help System, Fluent, Theory Guide.

[8] Munson B.R., Young D.F., Okiishi T.H., Fundamentals of Fluid Mechanics, John Wiley \& Sons, 1998.

[9] Basse N., Turbulence intensity and the Friction Factor for Smooth-and Rough-Wall Pipe Flow, Fluids, 2, 2017, 30.

[10] Saturated Vapour Pressure Calculator, http://ddbonline.ddbst.de/AntoineCalculation/ AntoineCalculationCGI.exe (access: 1.05.2017). 